\title{
chę
}

\section{Irmãs Anette Dumoulin, Ana Thereza e os romeiros de Juazeiro do Norte: entre missões e pesquisas científicas}

\author{
Núbia Ferreira Almeida \\ Doutora em Educação pela Universidade Federal do Ceará - UFC \\ Professora Adjunta da Universidade Regional do Cariri - URCA

\section{Zuleide Fernandes de Queiroz} \\ Doutora em Educação pela Universidade Federal do Ceará- UFC \\ Professora dos Programas de Pós-Graduação: Mestrado Profissional em Edu- \\ cação (MPEDU) Departamento de Educação - URCA
}

\section{Marlúcia Menezes de Paiva}

Doutora em Educação pela Pontifícia Universidade Católica de São Paulo $P U C / S P$

Professora Titular do Centro de Educação da Universidade Federal do Rio Grande do Norte - UFRN

\section{Resumo \\ Com as palavras "defender o Padre Cícero e acolher os romeiros", as freiras Anette Dumoulin (belga) e Ana Thereza (paulista) chegaram a Juazeiro do Norte-CE, na década de 1970, atraídas pela história de um Padre Santo no Nordeste. Professoras, doutoras em Ciências da Educação, especialistas em Ciências da Religião, saem de uma pesquisa sobre comunidades eclesiais de base para estudar o Padre Cícero e os romeiros. Passam a morar na cidade, onde realizam grandes obras educacionais e assistenciais em favor dos romeiros: O Semeador, o Poço de Jacó, a Escola Madre Alix, o Centro Catequético Francisca Inês e o Centro Paroquial de Assistência ao Romeiro. Além disso, fundaram a Congregação de Nossa Senhora (Ordem das Cônegas de Santo Agostinho). Este estudo reconstitui a trajetória de vida, a formação e a missão católica e educativa das freiras professoras.}

Palavras-chave ciências da religião; educação; Padre Cícero; romeiros.

Conhecer: debate entre o público e o privado 2018, Vol. 08, ํㅡ 21

ISSN 2238-0426

DOI: 10.32335/2238-0426.2018.8.21.1124

Licença Creative Commons Atribuição 


\begin{abstract}
With the words "advocating for Padre Cícero and welcoming pilgrims," the nuns Anette Dumoulin (Belgian) and Ana Thereza (Paulista) arrived in Juazeiro do Norte, Ceará, in the 1970s, attracted by the story of a Holy Father in Northeastern Brazil. Professors, holding a Ph.D. in Education Sciences, specialists in Studies in Religion, they left a research study on ecclesial base communities to analyze Padre Cícero and the pilgrims. So, they moved into the city and managed to create great education and social service works in favor of the pilgrims: 'O Semeador,' the 'Poço de Jacó,' the 'Escola Madre Alix,' the 'Centro Catequético Francisca Inês,' and the 'Centro Paroquial de Assistência ao Romeiro.' In addition, they founded the 'Congregação de Nossa Senhora (Ordem das Cônegas de Santo Agostinho).' This study reconstitutes the nun teachers' life history, education, and Catholic and educative mission.
\end{abstract}

Key words studies in religion; education; Padre Cícero; pilgrims.

\title{
Aspectos históricos e metodológicos
}

A renovação no domínio científico das Ciências Humanas, em particular nos estudos históricos, com a abertura proporcionada pela História Nova, possibilitou a pesquisa em campos de estudo antes impensados. Um desses campos foi denominado Estudos sobre Mulheres. O objetivo deste artigo é demonstrar a participação feminina em espaços educativos, pensando o espaço, de acordo com Certeau (1994, p. 202), como algo vivido, em movimento, como "um lugar praticado". O chamado Cariri cearense, que geograficamente abrange os municípios de Crato, Juazeiro e Barbalha, com extensão para Missão Velha e outras localidades menores, tem, até aos dias atuais, uma história entremeada de misticismo com forte atuação de padres/missionários, freiras e beatas na formação da identidade cultural, social e econômica das populações locais.

Segundo Della Cava (1976), um dos pioneiros dessas ações no Cariri foi o Padre Mestre Ibiapina (1806-1883), nascido na região, que, com a construção das primeiras casas de caridade, em Crato, Barbalha, Missão Velha e Milagres, e a criação de uma congregação religiosa de freiras, iniciou a educação feminina na região. Outro importante padre/ missionário foi o Padre Cícero Romão Batista (1844-1934), líder de um grande movimento místico na região, não se encontrando, porém, nenhum movimento educacional feminino em larga escala.

Partimos de uma abordagem micro-historiográfica da biografia, pois acreditamos que a trajetória de vida de 2 freiras professoras e pesquisadoras apresenta um significado maior do que enaltecer a trajetória de vida de 2 missionárias católicas, segundo o padrão da hagiografia, antigo estilo literário que buscava enaltecer a vida dos santos. Suas vidas se tornarão identificadoras de um sentido histórico mais amplo, visto que estudamos histórias de vida entrelaçadas por religiosidade, fanatismo, poder político, exclusão social e discriminação no cotidiano de uma cidade. Como diz Delory-Momberger (2008, p. 36): 
O espaço-tempo segundo o qual figuramos os limites de nossa existência é de fato aquele no qual nascem nossas histórias, ou seja, construções segundo as quais apreendemos nossa vida. Jamais atingimos diretamente o vivido. Só temos acesso a ele pela mediação das histórias.

Adotamos como técnica de pesquisa a História de Vida, utilizando documentos, bibliografia e depoimentos, com o propósito de compreender a construção dos valores e das ações dessas duas freiras, ao longo do tempo, como, por exemplo: origem e juventude, estudos e início da carreira, período de transição e o surgimento de uma nova vida em favor dos romeiros - esses temas estão distribuídos ao longo do texto. Como Delory-Momberger (2008, p. 37-38) anuncia:

[...] as histórias que contamos de nossa vida se escrevem sob as condições sócio-históricas da época e da cultura (das culturas) às quais pertencemos. Há uma história (uma historialidade) do "narrar a vida", como há uma história (uma historialidade) do "indivíduo", da "consciência de si", do "sujeito". As formas que toma a linguagem da narrativa em tal estado da sociedade, em tal relação do indivíduo com o político e o social, imprimem sua marca em nossas representações biográficas.

As irmãs Anette Dumoulin e Ana Thereza, cujas histórias de vida nos serviram de fontes, tiveram suas vidas entrelaçadas como missionárias e pesquisadoras da área de Psicologia da Religião e Religiosidade Popular, mas, encantadas pela peculiaridade da vida dos romeiros de Juazeiro do Norte-CE, durante visita ao município em 1974, selaram uma perspectiva de vida e objetivos comuns em uma frase:

Na serra do Catolé, Ana Thereza (sic) e eu tomamos consciência de que, no fundo, os estudos que tínhamos feito, no final, era para vir morar no Juazeiro, nesta dupla dimensão, para estudar o Padre Cícero, a verdade sobre a vida dele, e servir e acolher os romeiros. Pequei uma cabaça verde e escrevi "de todo jeito voltaremos a Juazeiro", em 14 de julho de 1974. (Irmã Annette, entrevista em 26 de maio de 2018)

Dispostas a tudo para alcançar seus objetivos, percebemos que nesta frase há um misto de amor, religiosidade e racionalidade afetiva. Sentimentos sem os quais seria impossível transpor as barreiras que atravessam decisões radicais de mudança, que afetam a vida em todos os seus aspectos, especialmente os financeiros e os culturais: 
Eu deixei pai e deixei mãe. Deixei todos os meus irmãos. E cheguei no Juazeiro,

para servir ao romeiro. (Irmã Annette, entrevista em 26 de maio de 2018)

Estas são palavras marcantes que ela sempre faz questão de ressaltar em suas falas, nos eventos para os quais é convidada.

Dentre os diversos religiosos que se instalam em Juazeiro do Norte para cumprir missão junto à Igreja Católica há um significativo número de pessoas vindas das mais diversificadas localidades brasileiras e estrangeiras, que contribuem decisivamente para o encontro de povos e culturas na cidade estudada neste artigo. Irmã Ana Maria Thereza Guimarães, pesquisadora da Universidade Louvain, situada na Bélgica, chegou a Juazeiro do Norte junto com a Irmã Anette Dumoulin para realizar uma pesquisa sobre o Padre Cícero. A imersão na cultura da cidade foi determinante para transformá-la, ao lado da Irmã Annette, em apoiadora do trabalho de romarias, deixando um legado muito importante para essa cidade, a chamada "Nação Romeira".

A valorização da figura do devoto romeiro foi um dos marcos de suas histórias de vida que causou uma verdadeira revolução no modo como a população local e a própria Igreja Católica passou a encarar o romeiro e o fenômeno das romarias, embora, por volta dos anos 1930 e 1940, a Professora Amália Xavier de Oliveira já tivesse feito advertências aos vigários, desde o Monsenhor Lima e a todos os vigários que o sucederam, até chegar ao Monsenhor Murilo, sobre a importância do romeiro no contexto social, econômico e religioso da cidade. Entretanto, a peculiaridade do trabalho exercido pelas irmãs se encontra no aprofundamento da fé, ponto de partida para elas recriarem a história da religiosidade popular em torno do Padre Cícero. Tal mudança de comportamento e mentalidade também influenciou a luta que hoje se trava rumo à canonização do Padre Cícero e o empenho de professores e demais intelectuais para que a população juazeirense valorize sua própria história.

O misto de mulheres devotadas à missão da Igreja Católica e de pesquisadoras acadêmicas atrai a atenção das pessoas interessadas nos serviços sociais por elas desempenhados e, especialmente, no trabalho de evangelização junto aos romeiros. Desperta, ainda, a curiosidade de pesquisadores e historiadores para a importância de reexaminar a história do Padre Cícero, da Beata Maria de Araújo e das romarias, em busca de uma nova interpretação que os aproxime de realidades locais nunca antes investigadas.

\section{As irmãs Ana Thereza e Annette: trajetória de vida}

As irmãs são membros da Congregação de Nossa Senhora (Ordem das Cônegas de Santo Agostinho). Fundada na cidade de Mattaincourt (França), em 1597 - por Alix Le 
Clerc, freira nascida em 1576 em Lorena (França), com o apoio de 4 companheiras e do Padre Pedro Fourier' -, seu lema era: "Fazer o bem a todos e o mal a ninguém". São Pedro Fourier morreu em 1640 e foi canonizado em 1897.

Essas jovens irmãs realizam seu trabalho em contextos sociais, políticos, religiosos e culturais conturbados, marcados por guerra, empobrecimento da população, reforma da Igreja Católica, injustiça social e ignorância. Nesse contexto, sua ação apresenta significativa influência social, proporcionando assistência aos doentes e necessitados e adotando especial olhar para a desvalorização e o desprezo da mulher na sociedade em questão.

O carisma da Congregação de Nossa Senhora (CSA) é "seguir Jesus construindo relações justas e fraternas para mudar o mundo". As irmãs enfrentam o desafio de dedicar-se à educação e valorização da mulher, por meio do ensino ofertado a meninas pobres com vistas a formá-las para que participem da vida em sociedade. Trata-se de uma ordem religiosa que se dedica à educação há mais de 400 anos. No Brasil, é mantenedora dos colégios e escolas que compõem a rede da Associação Instrutora da Juventude Feminina (AIJF) - instituição que pertence à CSA, sem fins lucrativos, cuja finalidade é levar educação e assistência social à juventude no Brasil e em todos os países onde a CSA se instalou.

A espiritualidade de Santo Agostinho se faz presente na inspiração do trabalho educacional, evangelizador e de toda a vida e ação apostólica dessas irmãs, com ênfase "no amor e na liberdade".

\section{Irmã Ana Thereza}

Therezinha Stella Guimarães, a Irmã Ana Thereza, nasceu em Guaratinguetá-SP. Seu parentesco com o primeiro santo brasileiro, Frei Antônio de Sant'Ana Galvão, evidencia a forte influência familiar que teve para a missão de vida religiosa que escolheu, bem como seu envolvimento como devota nos trabalhos missionários de evangelização na Basílica Nossa Senhora Aparecida. Formada em Pedagogia pela Faculdade Sedes Sapientiae, em São Paulo, entrou para a Congregação de Nossa Senhora (Ordem das Cônegas de Santo Agostinho) e realizou importante trabalho como educadora - foi diretora do Colégio Stella Maris, em Santos-SP. Viajou para a Bélgica com a intenção de estudar e, ao mesmo tempo, descansar depois de um período de enfermidade. Nessa ocasião, fez curso de aperfeiçoamento em Teologia e Psicologia na Universidade de Louvain. Defendeu com sucesso sua tese de doutorado em 1983, intitulada Padre Cícero e a Nação Romeira: estudo psicológico da função de um "santo" no catolicismo popular. Era professora do Seminário São José, em Crato-CE, escritora, religiosa e provincial da CSA em Juazeiro do Norte.

\footnotetext{
1 O fundador da Congregação de Nossa Senhora (CSA), São Pedro Fourier, nasceu em Mirecourt, pequena cidade próxima a Mattaincourt, em 1565. Cursou a Universidade de Pont-à-Mousson, fundada pelos jesuítas.
} 
Publicada em forma de livro (Guimarães, 2011), sua tese de doutorado exerceu influência como religiosa e devota do Padre Cícero ao integrar a comissão que organizou a festa dos 100 anos da fundação do município de Juazeiro do Norte, em 2011, e, também, ao participar da comitiva liderada pelo Bispo Dom Fernando Pânico para entregar o pedido de beatificação de Padre Cícero, no Vaticano. Foi uma das fundadoras da "Pastoral do Romeiro" - com sua sensibilidade de freira e psicóloga, fez importante trabalho no atendimento individual ao romeiro. Dedicou boa parte de sua vida à "Associação dos Artesãos da Mãe das Dores", criada pelas irmãs em 1984 - trata-se de uma oficina de artesanato onde os artesãos mais experientes ensinam aqueles que querem aprender, constituindo uma proposta de trabalho coletivo. A irmã faleceu em Juazeiro do Norte em 19 de maio de 2013.

\section{Irmã Annette}

Anne Dumoulin, a Irmã Annette, nasceu em Liége, na Bélgica, em 14 de julho de 1935. Ela é a "cantora dos romeiros" - título do qual se orgulha sempre que fala. Teve aulas de canto na adolescência e costumava cantar com seu irmão gêmeo, Pierre, acompanhando-a ao piano. Relata que muito mais do que estudar, gostava de cantar e foi com esse canto que ela se apresentou ao romeiro e ao povo da cidade quando sua voz ecoava na torre da Igreja Matriz de Nossa Senhora das Dores. Antes de ingressar na Universidade de Louvain, formou-se em Educação Física para cumprir uma exigência de sua família, que a aconselhou a ter uma formação escolar de nível superior antes de dedicar-se à carreira religiosa. Estudou na Universidade Católica de Louvain² ${ }^{2}$, onde se graduou em Ciências da Religião; também se formou em Psicologia da Religião e fez Licenciatura em Ciências da Educação, obtendo os títulos de mestre e doutora em Ciências da Educação, com especialidade em Psicologia da Religião. Teve como orientador o Prof. Dr. Antoine Vergote, ex-aluno do psiquiatra e psicanalista francês Jaques Lacan que desempenhou um papel importante na introdução da Psicanálise na Universidade de Louvain, na Bélgica. Foi, ainda, professora desta universidade. Seguir sua vocação foi uma decisão difícil, pois teve de deixar uma vida segura como professora de uma importante universidade europeia para seguir um caminho cuja escolha vinha apenas do coração.

Ultrapassada essa fase inicial, estava diante de novo impasse: a escolha da congregação que iria seguir. Devido ao seu espírito desbravador e aventureiro, desejava estar mais perto do povo, ter um contato mais próximo com culturas diferentes da sua, e identificou-se com o trabalho realizado com mulheres no Brasil pelas irmãs da CSA, por meio de um programa chamado Assistência ao Litoral de Anchieta (ALA) ${ }^{3}$. Ficou tão encantada com a possibilidade de realizar trabalho semelhante que pôs fim à sua indecisão entre seguir

$2 \quad$ Uma das mais reputadas universidades católicas não só da Bélgica, mas do mundo.

3 Obra pedagógica e missionária inspirada no espírito de São Pedro Fourier e Alix Le Clerc. 
carreira missionária com as irmãs beneditinas, com quem estudava, ou as Cônegas de Santo Agostinho, onde foi consagrada em $1^{\circ}$ de janeiro de 1960. Essa era sua identificação maior pela ação mais voltada aos problemas na terra, a convivência com os mais necessitados, ou seja, congregava ação e contemplação, consideradas por ela imprescindíveis para a vida de uma missionária católica, onde se misturam paixão e desejo de contribuir para a construção de um mundo melhor.

Segundo Anne Dumoulin:

\begin{abstract}
Eu sempre tive uma visão mais mundial, idealista. Quando eu era jovem, lembro que chegavam missionários vindos da China, até do lado, mais ao norte da Europa. Contavam coisas e eu ficava admirada! Eu desejava viver uma vida de aventuras, mas que fosse ligada a descobrir as pessoas, para me encontrar com elas e dar o melhor de mim. E isso era a descoberta de quem é Jesus Cristo na minha vida (Arraes, 2017).
\end{abstract}

As irmãs chegaram ao Brasil em 1973, à época da Ditadura Militar, no mesmo período em que parte da Igreja Católica se posiciona ao lado dos pobres em uma caminhada de luta pela justiça social e pela democracia, alinhando-se aos que criticavam a visão autoritária de organização da sociedade e os métodos de combate aos comunistas e aos chamados "subversivos". Uma "Comunicação pastoral ao povo de Deus" diz:

\footnotetext{
O treino para essa guerra anti-subversiva, na América Latina, contra o comunismo, além de levar ao embrutecimento crescente de seus agentes, gera um novo tipo de fanatismo, um clima de violência e de medo. São sacrificadas as liberdades de pensamento e de imprensa, são supressas as garantias individuais (Conferência Nacional dos Bispos do Brasil [CNBB], 1976, p. 23).
}

Em 1976, a Comissão Representativa da Conferência Nacional dos Bispos do Brasil (CNBB), reunida no Rio de Janeiro, reconheceu que a violência recai sobre a própria Igreja Católica quando esta se posiciona ao lado do povo.

\title{
Transição: a chegada a Juazeiro do Norte e a atuação educacional
}

No período em que a Irmã Thereza esteve na Bélgica, a Universidade de Louvain ofereceu à Irmã Annette a oportunidade de fazer um curso de especialização em Psicologia 
da Religião no Brasil. Seu percurso no país tomou um rumo diferente do planejado inicialmente quando as irmãs realizaram suas pesquisas juntas, no Nordeste. Em Recife, estudaram durante um ano na "Escola Dos Pobres", nas Comunidades Eclesiais de Base (CEBs).

Os pobres foram nossos professores. Você imagina, uma mudança quase radical, vir da Europa, com uma religiosidade totalmente diferente encontrar aqui os romeiros, aprendendo uma língua. (Annette, entrevista em 26 de maio de 2018)

Apoiadas por Dom Helder Câmara, na vigência da Ditadura Militar, instalaram-se em Beberibe, bairro na periferia do Recife, local conhecido pelo alto índice de violência e pobreza, porém, a intenção era estabelecer uma aproximação com a realidade local e elas realizaram suas pesquisas em meio aos trabalhos com as CEBs. Iniciaram seus trabalhos no Brasil em um dos períodos mais fecundos da história da Igreja Católica. O objetivo dessas pesquisas era descobrir como nasciam as lideranças religiosas nessa área dinâmica da cultura popular, perseguida pelo regime militar da época" (Guimarães, 2011).

Não fazia parte de seus planos morar em Juazeiro do Norte, essa aventura ocorreu por acaso, como a Irmã Annette conta em palestra proferida no Memorial Padre Cícero, em $2017^{4}$, bem como em entrevista. Nessas ocasiões a Irmã Annette contou que viu um quadro do Padre Cícero pendurado na parede da sala de uma vizinha, em Recife; ela ficou curiosa e perguntou à Irmã Thereza: "quem é este homem?". A irmã lembrava apenas que se tratava de um padre cuja história causou polêmica na Igreja por ter sido líder de um movimento religioso popular.

Essa curiosidade em relação ao quadro do Padre Cícero instigou sua vontade de ir a Juazeiro, então, receberam o convite dos pais de Maninha, uma vozinha que morava em Recife. Aceitaram sem hesitação. Nos 10 dias que ali, passou na companhia de Selvina, a lavadeira da família, que por coincidência havia sido moradora do Caldeirão, do Beato João Lourenço, a Irmã Annette ouviu suas histórias enquanto Ihe mostrava a cidade. Imagine-se a aventura fantástica que as irmãs viveram, imbuídas tanto pelo espírito de religiosidade como de pesquisa, ao caminhar em companhia de uma pessoa que representa como ninguém o espírito dessa cidade - uma devota do Padre Cícero.

Decerto, encontraram uma "mina a céu aberto", como narra a Irmã Annette. Ela conta que, junto com a Irmã Thereza, estava diante de um novo impasse: continuar com sua pesquisa em Recife ou ficar definitivamente em Juazeiro do Norte? Em 1974, a decisão foi tomada em uma festa de São João, no Horto, lugar onde se encontra a estátua do Padre Cícero. Entretanto, não se pode deixar de mencionar uma questão política importante: a perseguição dos militares aos religiosos que se posicionavam ao lado dos pobres.

$4 \quad$ I Festa do Livro de Juazeiro do Norte, realizada em 10 e 11 de agosto de 2017. 
A Irmã Annette conta um fato curioso que pode ser relacionado à Ditadura Militar, especialmente ao se levar em conta o posicionamento da Igreja Católica naquele momento, em favor dos pobres:

Em 1973, chegamos em Recife e depois de um ano viemos conhecer Juazeiro. Quando voltamos para Recife, a nossa casa tinha sido roubada. As pessoas que nos receberam lá, nas comunidades eclesiais de base, acharam que podia não ser roubo normal. Então, decidimos vir morar em Juazeiro, pois o contexto da Ditadura Militar, a gente percebia que era perigoso. (Annette, entrevista em 26 de maio de 2018)

A Europa ficou mais distante de sua história particular, pois tinha assumido a missão de consagrar sua vida à pastoral com os romeiros. Justificou sua decisão com base na religião, que, naquele momento, parecia mais importante do que a pesquisa e a carreira como professora de uma importante universidade europeia:

O desprezo que a Igreja teve com o Pe. Cícero e os romeiros foi o que me fez ficar aqui. Os romeiros chegavam com fome e sede da palavra de Deus e eram desprezados, condenados. Isso, como pesquisadoras, nos deixou chocadas, mas como cristãs foi tão forte que nos motivou a largar a universidade (Arraes, 2017).

A escolha da congregação foi importante para o desenvolvimento de suas atividades como religiosas, pois trouxe a liberdade de refletir sobre o que ela representaria dentro da Igreja Católica, na qualidade de mulher e intelectual, para confrontar as atitudes machistas que conduziam a hierarquia eclesial e, assim, realizar um trabalho voltado à inserção mais justa e igualitária da mulher e dos menos favorecidos na sociedade. Dessa reflexão nasceram inúmeros projetos de trabalho com a comunidade juazeirense e com os romeiros.

O Padre Murilo teve, inicialmente, preocupação com a nossa chegada. Se preocupava como seria nossa ação. O Padre Murilo nos deu condições de trabalhar, muito observador, e uma vez que ele tomou confiança, ele respeitou nossa condição e fizemos um trabalho de equipe. Ele era um homem que compreendia as mulheres... (Annette, entrevista em 26 de maio de 2018)

Em 1976, as irmãs se estabelecem em sua própria casa na Rua Padre Cícero, em Juazeiro do Norte, acolhidas pelo vigário da cidade, o Padre Murilo de Sá Barreto, e o 
Padre José Alves. Com seu apoio, inicialmente, abriram o Centro de Psicologia da Religião, com vistas a dar continuidade às suas pesquisas. Depois veio o Centro de Acolhimento ao Romeiro, na Matriz de Nossa Senhora das Dores. A decisão de continuar com a pesquisa era imperativa para conhecer o universo místico e simbólico dos romeiros e melhorar o desempenho de suas ações dentro da Igreja. Destaca-se, também, que a Irmã Annette foi professora de Psicologia da Religião e Religiosidade Popular no Seminário da Prainha, em Fortaleza ${ }^{5}$.

\section{Obras que fundaram em Juazeiro do Norte}

Dar voz aos romeiros tem um significado histórico importante porque permite examinar a cultura e a sociedade não mais ou apenas sob o ponto de vista do poder instituído, oficial, mas sob a perspectiva popular, marginal - é a chamada "História Vista de Baixo", segundo Edward Thompson, que utilizou o termo pela primeira vez no artigo "History from Below", publicado no The Times Literary Supplement em 1966.

O que eu gostei no Juazeiro é a experiência do Romeiro. O que nos atraiu foi a iniciativa popular da romaria. Realizamos uma ação pedagógica dentro da romaria, a partir dos romeiros. A gente descobre o valor no olhar do outro. (Annette, entrevista em 26 de maio de 2018)

No Círculo Operário de Juazeiro, todos os dias, a irmã Annette empresta o microfone aos romeiros para que eles expressem suas opiniões e emoções e compartilhem suas histórias. Trata-se, sem dúvida, de uma das grandes contribuições de seu trabalho, pois alimenta o espírito da fé dos romeiros, ao mesmo tempo que os faz ser ouvidos pelos que os ignoram, bem como cria uma fonte de pesquisa para diversas áreas das Ciências Sociais:

E esse instrumento que poderia ser de manipulação, se transformou em arma de expressão. (Annette, entrevista em 26 de maio de 2018)

E a Irmã Annette cita o Padre Murilo, que dizia:

5 O Seminário da Prainha é uma instituição católica de formação eclesiástica da Arquidiocese de Fortaleza, que serve a diversas dioceses, ordens e congregações religiosas para a formação de padres, religiosos e leigos. Está situado no centro histórico de Fortaleza. 
O romeiro tem valor, uma romaria que vem de baixo, como ele foi perseguido, ele vem pra Juazeiro, com o padre, sem o padre e contra o padre. Ele não briga com seu pároco, mas ele vem todo ano. Pois se fosse pela Igreja, inicialmente, ele não viria. (Annette, entrevista em 26 de maio de 2018)

A Rede Alix faz parte da CSA. Além do Brasil, possui outras unidades na Europa, na Ásia e na África. Trata-se de comunidade escolar com cerca de 40 mil alunos em todos os países. As obras criadas em Juazeiro do Norte integram essa rede, como se descreve a seguir.

\section{O Semeador}

Fundada em 1988, como Centro de Educação Comunitária, é uma entidade de natureza filantrópica. Realiza um trabalho de educação integral e formação humana social, religiosa, artística, psicológica, ecológica, intelectual e profissional - junto às famílias e crianças pobres que vivem em seu entorno, situado no bairro Aeroporto, em Juazeiro do Norte. Iniciou suas atividades com uma classe de pré-escola e um grupo de alfabetização de adultos, além de horta, granja, artesanatos diversos e piscicultura - criação de tilápia para a produção de suplemento alimentar fornecido às crianças e suas famílias (Escola $\mathrm{O}$ Semeador, n.d.).

Considerada uma das obras mais importantes das freiras, o espaço para realizar o trabalho missionário foi designado "O Semeador". Após a constituição da Associação Instrutora da Juventude Feminina, que tinha a intenção de implementar um Projeto de Horta Comunitária com 10 famílias carentes do bairro. Entretanto, essa experiência não permaneceu. Em seguida, a partir de levantamento junto à comunidade das necessidades das famílias, o grupo detectou a falta de instituição para acolher crianças. Assim, a Escola O Semeador (n.d.) foi criada em 1988, como "entidade educativa de natureza filantrópica, cujo nome nasceu de um sonho: fazer de um pedaço de terra arenosa um espaço fértil, bonito, onde crianças pobres pudessem crescer felizes no meio de uma natureza cheia de flores e frutas".

As ações da instituição consistiram na oferta de classes de pré-escola e educação de adultos e iniciativas de geração de renda, como: horta, granja, padaria-escola, produção de artesanato e piscicultura. As freiras tiveram apoio de organizações não governamentais (ONGs) da França e da Alemanha, com repasse da merenda escolar em parceria com a Prefeitura Municipal, por meio de recursos do Fundo Nacional de Desenvolvimento da Educação (FNDE). Foram organizadas oficinas de Bordado a Mão, Tecelagem, Computação, Pintura em Tecidos, Vagonete, Artesanato em Palha de Milho e Crochê. 
O projeto foi se ampliando e passou a oferecer educação infantil regular, com turmas de Maternal, Jardim I e Jardim II e trabalhos na área de Orientação Escolar. Em 2006 foi criada a Creche/Berçário e uma classe de 1aㅗ série do Ensino Fundamental. Em 2008 foi aberta uma classe de $2^{\text {a }}$ série do Ensino Fundamental. Houve necessidade de ampliar o espaço e de deslocar atividades para o Sítio Carnaúba. Em 2009 foram organizadas novas oficinas de Bordado a Mão e Pintura em Tecidos. A parceria com o Governo do Estado do Ceará possibilitou a aquisição de móveis e equipamentos. Atualmente, a instituição possui uma Orquestra com Deficientes Visuais e, em parceria com o Serviço Social do Comércio (Sesc), disponibiliza a adolescentes e jovens cursos de Teatro e Artes, além de 3 oficinas para as crianças da escola: Artesanato para o Infantil V; e Artes Visuais e Teatro para a $1^{\text {a }}$ e $2^{\text {a }}$ séries do Ensino Fundamental. A escola atende 253 crianças nos turnos matutino e vespertino, com idades entre 2 e 7 anos (classes do Infantil II, III, IV, V e da $1^{\underline{a}}$ e $2^{\underline{a}}$ séries do Ensino Fundamental), residentes nos bairros Aeroporto, Timbaúbas, Pedrinhas, Petrolândia, Limoeiro, Leandro Bezerra e em localidades vizinhas, como Vila Carité, Sítio Brejo Seco e Campo Alegre (Escola O Semeador, n.d.).

\section{O Poço de Jacó}

A Escola Poço de Jacó foi criada como uma creche, em 1988, e está localizada na Vila Bom Jesus, no Horto - um dos bairros mais pobres da cidade. Começou com 2 salas de aula, 1 cozinha e 1 banheiro. De 1988 a 1995 ela atendia cerca de 100 crianças e 15 jovens e adultos em suas diferentes oficinas. Em 1995, a Paróquia de Nossa Senhora das Dores e a AIJF fizeram uma parceria para ampliar o espaço físico e, consequentemente, atender a maior número de crianças. Em 1996, a creche passou a ser mantida pela AIJF. Em junho de 2011, a creche passou a ser, oficialmente, Escola Poço de Jacó. Atualmente, é composta por 7 salas de aula, 1 sala para reeducação pedagógica, 1 sala de música, 1 sala para oficinas e artesanatos, 1 laboratório de informática, 4 banheiros, 1 cozinha e 1 salão. Atende uma média de mais de 500 pessoas por ano.

\section{A Congregação de Nossa Senhora (Ordem das Cônegas de Santo Agostinho)}

A congregação está presente na Paróquia de Nossa Senhora das Dores - Basílica Santuário - desde a chegada das irmãs Ana Thereza e Annette Dumoulin. Despertadas pelo carisma da CSA e de suas formadoras, seguem os ensinamentos de São Pedro Fourier e Alix Le Clerc. O movimento tem como missão ser "Sal da Terra e Luz do Mundo" (Mateus 5,13-14). Vivencia a proposta da "Igreja em Saída”, assim, seus membros atuam em diversas pastorais e movimentos da Basílica de Nossa Senhora das Dores e de outras paróquias de Juazeiro do Norte. 
Foi assim que suas obras tiveram início em Juazeiro do Norte, como afirma Walker (2013):

\footnotetext{
Para entender o fenômeno das romarias e penetrar mais fundo no universo cultural e religioso dos romeiros, [a Irmã Thereza] e sua inseparável amiga e colega Annette fundaram com o incentivo do padre Murilo o Centro de Psicologia da Religião, local onde foram produzidos e divulgados muitos trabalhos sobre $\circ$ Padre Cícero, as romarias e a religiosidade popular.
}

Em Juazeiro do Norte, a congregação possui espaços próprios para a realização de ações educacionais e assistenciais e as freiras participam diretamente das ações empreendidas pela Igreja Católica no Cariri cearense, além de disponibilizar uma ampla produção intelectual e catequética para divulgar a ação missionária do Padre Cícero em diálogo com os romeiros e com os estudos acadêmicos.

\section{O Centro Paroquial de Assistência ao Romeiro}

De acordo com Walker (2013), "no dia 26 de maio de 2012 foi inaugurado o Centro Paroquial de Assistência ao Romeiro [CPAR], órgão da Basílica de Nossa Senhora das Dores, o qual recebe o seu nome".

O CPAR oferece serviços aos devotos do Padre Cícero durante as romarias. No local, as pessoas fazem um cadastro que possibilita o reconhecimento de todos, um serviço de utilidade pública. O espaço conta com equipamentos, bebedouros, banheiros e uma área de convivência, para descanso e conversa, "enquanto [os romeiros] aguardam a celebração de atos religiosos" (Walker, 2012).

\section{Conclusões}

Este estudo possibilitou a identificação nas histórias de vida das freiras em análise, "mulheres religiosas" que, mesmo vivendo sob a dominação eclesiástica masculina, buscaram suas próprias formas de resistência. Annette e Thereza afirmaram que se engajar em uma congregação de base romana, mas não diocesana, proporcionou a liberdade necessária para pensar suas práticas religiosas e sua formação acadêmica, pois são poucas as mulheres na Igreja Católica com formação superior e doutoramento. Assim, constatamos que as relações de gênero constituídas na sociedade não estão simplesmente ligadas às relações entre homens e mulheres, tomá-las dessa forma seria simplificar as desigualdades de gênero que privilegiam uma classe dominante, que encontra nas religiões a manutenção 
e o controle dessa dominação; ao homem cabe todo o poder da construção e coordenação das práticas religiosas, às mulheres resta apenas a submissão.

No Brasil, as ações realizadas por freiras sempre foram direcionadas ao amparo das camadas sociais desassistidas de políticas governamentais e em situação de risco. Elas também atuam nos campos da educação e da saúde, abrindo caminho para as mulheres nas profissões que neles se enquadram desde a época em que "a maioria da população feminina [ainda] era do lar" (Nunes, 2007, p. 482).

A história das irmãs Annette e Thereza constituiu marcas que vão além de controle e submissão, permitindo observar transgressões e resistências que ultrapassam os limites impostos pela sociedade e suas instituições de controle para a vida das mulheres. As freiras aqui estudadas, na verdade, são autoras de sua própria história e, ao mesmo tempo, são parte da história de Juazeiro do Norte, pois redefiniram a atuação feminina no espaço de uma instituição religiosa católica.

O fenômeno das romarias passou por uma real modificação no que se refere à valorização dos romeiros devotos do Padre Cícero e de Nossa Senhora das Dores, fato que causou, também, significativas mudanças no modo como a população local e a própria Igreja Católica passaram a encarar o romeiro e o fenômeno das romarias, ressignificando a história da fé e da religiosidade popular.

Pesquisadoras acadêmicas e religiosas, elas realizaram importante trabalho como missionárias da Igreja Católica, com atuação cultural marcante no incentivo às artes populares, por exemplo. A evangelização junto aos romeiros se apresenta de modo peculiar, em um misto de psicologia e religião. Despertaram, ainda, a curiosidade de pesquisadores e historiadores para a importância de reexaminar a história do Padre Cícero, da Beata Maria de Araújo e das romarias, em busca de uma nova interpretação que os aproxime de realidades locais nunca antes investigadas.

\section{Referências bibliográficas}

Arraes, R. (2017, 29 de março). O templo e o caminho. Recuperado de https://caririrevista.com.br/o-templo-e-o-caminho/

Certeau, M. (1994). A invenção do cotidiano: artes de fazer. Petrópolis, RJ: Vozes.

Conferência Nacional dos Bispos do Brasil. (1976). Comunicação pastoral ao povo de Deus. Recuperado de file:///H:/08-Comunica\%C3\%A7\%C3\%A3o-Pastoral-ao-Povo-de-Deus.pdf

Della Cava, R. (1976). Milagre em Joaseiro. Rio de Janeiro, RJ: Paz e Terra.

Delory-Momberger, C. (2008). Biografia e educação: figuras do indivíduo-projeto. Natal, RN: Ed. UFRN. 
Escola O Semeador. (n.d.). História. Recuperado de http://www.redealix.org.br/osemeador/historia/ Guimarães, T. S. (2011). Padre Cícero e a Nação Romeira: estudo psicológico da função de um "santo" no catolicismo popular. Fortaleza, CE: IMEPH.

Nunes, M. J. R. (2007). Freiras no Brasil. In M. D. Priore (Org.), História das mulheres no Brasil (pp. 405- 427). São Paulo, SP: Contexto.

Rolim, L. C. (1998). Semeadoras da esperança: "ALA - uma forma de educar”. São Paulo, SP: Loyola. Walker, D. (2012, 27 de maio). Basílica inaugura Centro de Assistência ao Romeiro. Recuperado de http://www.portaldejuazeiro.com/2012/05/

Walker, D. (2013, 18 de maio). Faleceu Irmã Tereza. Recuperado de http://www.portaldejuazeiro. com/2013/05/faleceu-irma-ana-teresa.html 